\title{
Liver Fluke, Opisthorchis viverrini, Vaccine - The Future Hope
}

\author{
Wiwanitkit $\mathrm{V}$ \\ Professor, Hainan Medical University, China
}

\section{*Corresponding Author:}

VirojWiwanitkit,

Professor, Hainan Medical University, China.

Tel: +0086-931-2938310

E-Mail: wviroj@yahoo.com

Recieved: June 02, 2015

Published: June 08, 2015

Citation: Wiwanitkit V (2015) Liver Fluke, Opisthorchis Viverrini, Vaccine - The Future Hope. Int J Vaccines Res. 02(1e), 1.

doi: http://dx.doi.org/10.19070/2572-7427-150002e

Copyright: Wiwanitkit $\mathbf{V}^{\mathbb{O}} 2015$. This is an open-access article distributed under the terms of the Creative Commons Attribution License, which permits unrestricted use, distribution and reproduction in any medium, provided the original author and source are credited.

Liver fluke, Opisthorchis viverrini, is an important parasite that can cause chronic biliary tract infestation and can further induce a deadly cancer namely cholangiocarcinoma. This infestation is endemic in Southeast Asia, at Mekong River Indochina Region. At this area, there is a very high incidence of cholangiocarcinoma. The prevention of this disease is the present public health policies of the local government. The campaign composing of abstinence from raw fish intake, routine stool examination and mass antiparasitic drug treatment is used. However, the problem is not successful managed. The use of the liver fluke vaccine is the hope for the future successful disease control. There are some recent reports on this aspect. The searching for proper antigenic proteins and epitopes is very interesting. Generally, the search of the egg shell protein of liver fluke can be the first step for further liver fluke vaccine development [1]. However, the important problem is the change of molecular structures of parasite during the transition from the juvenile to the adult stage. This can make antigenic protein finding more difficult [2]. Comparative proteomics analysis has been continuously done by the medical scientist to assess the difference due to the mentioned transitioning [3] but it is still not successful. Indeed, on the other hand, the study on serotome can also be way to find the vaccine [4]. Nevertheless, this is not already studied for the case of $O$. viverrini. It seems that there will be a very long way to reach the goal, having the effective vaccine towards O. viverrini. However, there are many obstacles on researching and development to be mentioned. First, the disease occurs in the poor region of the world. Without funding, there are very few researchers working in this area. Also, without the technology, development of vaccine by hi-tech laboratory is not possible. Second, as a tropical infection in poor countries, the drug and vaccine companies usually overlooks this infestation and do not pay attention for research and development in this field. Finally, the local public health sector might not believe that the vaccine can be the last long preventive method comparing to the simple last long done but not effective general practice.

\section{References}

[1]. Wiwanitkit V (2014) Finding for epitope within egg shell protein of human liver fluke: A clue for cholangio carcinoma vaccine development. South Asian J Cancer. 3(2): 142-143.

[2]. Jex AR, Young ND, Sripa J, Hall RS, Scheerlinck JP, et al. (2012) Molecular changes in Opisthorchis viverrini (Southeast Asian liver fluke) during the transition from the juvenile to the adult stage. PLoS Negl Trop Dis 6(11): e1916.

[3]. Boonmee S, Imtawil K, Wongkham C, Wongkham S (2003) Comparative proteomic analysis of juvenile and adult liver fluke. Opisthorchis viverrini. Acta Trop. 88(3): 233-238.

[4]. L'vova MN, Duzhak TG, TsentalovichIuP, Katokhin AV, Mordvinov VA (2014) Secretome of the adult liver fluke Opisthorchis felineus. Parazitologiia 48(3): $169-184$ 